\title{
A IMPORTÂNCIA DA HISTÓRIA E DA LINGUAGEM PARA A IDENTIDADE DO JURISTA
}

\author{
Ângela Kretschmann ${ }^{1}$
}

\begin{abstract}
Resumo
O texto aborda os desafios da comunicação para o operador jurídico e a importância da compreensão do ser que é a linguagem para a construção identitária do próprio sujeito, a partir de uma memoria que dá vida e liberta, e que o torna capaz de instituir e construir sua própria história de vida, e nela, sua carreira jurídica. O livro de Orwell, para o jurista, revela-se como permanente sinal de alerta para o operador jurídico, para que não seja seduzido por um pensamento exclusivamente apodítico, onde o Direito é visto como uma verdade normativista, posta, desconectada de todo caráter vinculativo da realidade social.
\end{abstract}

\section{Palavras-chave: direito, linguagem, 1984, identidades}

\begin{abstract}
The article discusses the challenges of the language and communication to the legal operator and the importance of understanding the being that is the language for the consruction of subject identity, from a memory that gives life and releases, and that give conditions, or make the legal operator able to establish and build their own life history, and in it, his legal career. Orwell's book revelas for the legal student and operator himself as permanent reminder, to not being seduced by one thought exclusivelly apodictic, where the law is seen as a normative truth, instituted and disconnected from all binding character of social reality.
\end{abstract}

\section{Keywords: law, language, 1984, identities}

\footnotetext{
${ }^{1}$ Pós-doutorado em Direito pela Universidade de Münster, Doutora em Direito pela Unisinos, Mestre em Direito pela PUC/RS, Professora de Direito da Propriedade Intelectual na Unisinos e no Cesuca.
} 


\section{Direito e Linguagem}

Tudo que é percebido pelos sentidos e é recolhido pela linguagem, passa a constituir a realidade, inclusive a realidade jurídica. Assim é que a própria Filosofia da Linguagem conquistou seu lugar no plano jurídico. O livro "1984” de George Orwell permite tantas abordagens jurídicas que se impõe uma delimitação preliminar. No presente artigo será privilegiada a análise da importância da linguagem, da comunicação, para o direito, pois é na dimensão da linguagem que o direito encontra sua dimensão real.

Entenda-se, por outro lado, que o intérprete de um texto precisa deixar que o texto oriente a compreensão, tornando o texto e o tema acessíveis, sendo que para isso precisa também estar apto a falar a língua, sob pena do total prejuízo de um diálogo entre o interprete e o texto, ou como quer Gadamer, sob pena da impossibilidade da fusão de horizontes. Como nos lembra bem Richard Palmer: Experimentemos por exemplo pedir a alguém que não fale alemão, que oiça um poema de Goethe e que diga se o acha bonito ou feio”. Sem ela, o diálogo com o texto legal não tem como existir, muito menos a fusão de horizontes. ${ }^{2}$

Direito e linguagem são, assim, indissociáveis, pois dissociar o Direito da Linguagem será privá-lo de sua própria existência, porque, ontologicamente, ele é linguagem e somente linguagem. ${ }^{3}$ Não é de se espantar que o domínio do Direito sempre dependeu de um bom conhecimento da língua, para melhor compreendê-la, melhor expressá-la. Aquele que pretende dominar o Direito precisa, naturalmente, antes dominar a língua, precisa entender o que se comunica, e o como comunicar. De fato, somos forçados "a admitir que as significações formam um texto que não se extrai da consciência ou da realidade, senão da própria circulação discursiva", quer dizer, como refere Warat, que é necessário "admitir a existência de um princípio de

\footnotetext{
${ }^{2}$ PALMER, Richard E. Hermenêutica. Trad. de Maria Luísa Ribeiro Ferreira. Edições 70: Lisboa, 1997. p. 239.

${ }^{3}$ CALMON DE PASSOS, J.J. Revista de Processo, v. 102. Instrumentalidade do Processo e devido processo legal. São Paulo, 2001. P. 64.
} 
intertextualidade pelo qual aprendemos que o sentido de um texto depende de sua própria história, e esta do diálogo surdo com os outros textos de uma cultura". ${ }^{4}$

É assim que George Orwell nos coloca de forma muito clara, através da obra “1984”, o quanto a eliminação das palavras e da história obscurece a capacidade de pensamento e articulação - e o quanto é fundamental para uma ditadura apossar-se, dominar as palavras e o quanto pode significar, para a manutenção de uma ditadura, dominar as palavras e o modo como podem ser produzidas - e escrever a própria história. No mesmo sentido, a própria redução das palavras também contribui para a dominação e manutenção do poder:

Era impossível saber qual das versões acabaria sendo adotada, porém Winston acreditava firmemente que seria sua. O camarada Ogilvy, que até uma hora antes não existia nem na imaginação, agora era um fato. Não deixava de ser curioso, pensou Winston, que fosse possível criar homens mortos, mas não homens vivos. $\mathrm{O}$ camarada Ogilvy, que nunca existira no presente, agora existia no passado, e tão $\operatorname{logo}$ o ato da falsificação caísse no esquecimento, existiria com a mesma autenticidade e com base no mesmo tipo de evidência que Carlos Magno ou Júlio Cesar. ${ }^{5}$

Na ficção tão milimetricamente elaborada de Orwell, na medida em que o dicionário foi se reduzindo, menos se tornava possível fazer referências, relações, comparações, citações... e mais o poder poderia manipular a própria realidade, através da manipulação da linguagem. Por isso o romance de Orwell revela um valor peculiar para o jurista, como um aviso ou um lembrete, sobre a importância da linguagem.

E é claro, o dicionário só foi se reduzindo porque uma Lei assim impôs, uma vez que aquilo que é da natureza, e não é possível impedir que seja, só pode ser vencido pelo artificialismo de uma lei, tornando o que é natural, um ato ilegal, proibindo-o. Ou seja: se alguma manifestação é absolutamente natural, como a comunicação e a criação de novas palavras e nova forma de expressão, também só há

\footnotetext{
${ }^{4}$ WARAT, Luis Alberto. Introdução geral ao direito I: interpretação da Lei, temas para uma reformulação. Sérgio Fabris: Porto Alegre, 1984. P. 14.

${ }^{5}$ ORWELL, George. 1984. Trad. De Alexandre Hubner e Heloisa Jahn. São Paulo: Companhia das Letras, 2009. P. 62-63.
} 
uma forma de proibir que essa natureza se manifeste, que é tornando a própria manifestação um ato ilícito.

Com isso, a limitação da linguagem espelha sobre o direito uma limitação programada sobre seu próprio sentido. Inibe o diálogo sobre o Direito e o calcifica, espelhando um dogmatismo que se pretende inquestionável. Como disse Warat: $a$ castração da linguagem é um modo de fechar nossos olhos, pelo favor ao distinto, a tudo que não é conjuntamente verossímil e consagrado culturalmente. ${ }^{6} \mathrm{E}$ um direito que se revela como inútil, tanto quanto inexistente, ou mesmo pior do que isso, pois cria apenas obrigações que se legitimam por imposição de uma historicidade artificial, e não por uma historicidade legitimadora, de tal modo que o Direito possa servir aos interesses também pouco legítimos de um determinado grupo.

\section{Direito e Comunicação}

A comunicação, possível através da linguagem, é também o próprio ambiente do Direito. Portanto, não é simplesmente um instrumento. É praticamente o próprio viver do direito, uma vez que é através dela, a partir dela e, finalmente, com e exclusivamente por meio dela (reconhecendo o ser que é), que o jurista consegue efetivamente viver o Direito e exercer sua função, enquanto jurista. Lembra-nos MacIntyre que a excelência política, e "acima de tudo, a excelência do legislador consistem em ser bom em ordenar bens tanto em geral como em situações particulares", o que não significa que os únicos bens visados por uma comunidade sejam exclusivamente políticos, não havendo qualquer incompatibilidade entre a busca da virtude cívica e da virtude individual. E é no desempenho do papel social

\footnotetext{
${ }^{6}$ WARAT, Luis Alberto. A ciência jurídica e seus dois maridos. 2a. ed. Santa Cruz do Sul: EDUNISC, 2000. p. 14-15. E ainda adiante, explicativo: A gênese da castração é uma gênese de dominação. Qualquer dominação começa por proibir a linguagem que não está prevista e sancionada. Quadro dramático, quadro dogmático, que bem define como capador-capado o campo do imaginário instituído: jurídico, educacional, científico, amoroso, cotidiano. É o imaginário onde se produz um frágil equilíbrio entre castrações e sublimações e que faz crer que, quebrado esse equilíbrio, o homem tende ao autoritarismo. Nesse sentido, o discurso jurídico existe para fazer crer que há menos autoritarismo (p. 16).
} 
que o ser humano é projetado para o aperfeiçoamento de sua própria alma na atividade contemplativa. ${ }^{?}$

Enquanto isso, Orwell nos apresenta o retrato da situação oposta, da diminuição de palavras, da restrição de seu uso, do lento desaparecimento, do empobrecimento da linguagem. Ainda que ele não explore de modo ostensivo na obra, permite-nos enfrentar e desenvolver o problema de uma humanidade limitada a certo rol de palavras.

De certa forma, o livro demonstra de forma bastante exagerada o modo como a escravidão se perpetua, após o abolicionismo, de uma forma bastante opaca, ou simplesmente, subliminar. O que chama atenção é que apesar do exagero das imagens descritas, de uma criatividade absurda em relação a novas expressões e palavras que o autor desenvolve, como a "novafala" ou "novilíngua", e "crimideia", coloca o contraste de um governo que busca restringir o acesso e uso das palavras. Assim o leitor tem o prazer de deleitar-se com a experimentação de novas palavras, durante a leitura, ao mesmo tempo em que a história descrita é de sua diminuição. Um contraste acentuado e que permite valorizar ainda mais a sede por palavras.

E ao mesmo tempo em que no romance-ficção de Orwell as palavras vão cada vez desaparecendo mais do uso quotidiano, mais torna-se clara, e com verdadeiro horror, as possibilidades de diminuição real da liberdade, tão duramente buscada e alcançada, em vários sentidos. O livro descreve e nos exemplifica de que modo é possível, nos dias de hoje, viver preso com a certeza de que se é livre, e se a esfera privada era a única em que a liberdade era preservada, no livro sequer essa esfera sobrevive.

Novamente o livro de George Orwell revela-se de extrema importância como instrumento permanente de alerta para o operador jurídico. As condições em que são instituídas verdades pela esfera pública, e mesmo pela esfera privada, na atualidade, em especial, com os meios de comunicação nas mãos de poucos conglomerados internacionais, poderíamos nos questionar sobre até que ponto efetivamente a

\footnotetext{
${ }^{7}$ MACINTYRE, Alasdair. Justiça de Quem? Qual Racionalidade? Trad. Marcelo Pimenta Marques. Edições Loyola: São Paulo, 1991.p. 122.
} 
verdadeira realidade é aquela que estamos constantemente acompanhando pelo que nos chega pelos noticiários:

O Partido dizia que a Oceânia jamais fora aliada da Eurásia. Ele, Winston Smith, sabia que a Oceânia fora aliada da Eurásia não mais de quatro anos antes. Mas em que local existia esse conhecimento? Apenas em sua própria consciência que, de todo modo, em breve seria aniquilada. E se todos os outros aceitassem a mentira imposta pelo Partido - se todos os registros contassem a mesma história -, a mentira tornava-se história e virava verdade. "Quem controla o passado, controla o futuro; quem controla o presente, controla o passado", rezava o lema do Partido. ${ }^{8}$

E assim o próprio sentido ganha sentido, institucionalizado por meio de um Partido que escolhe o destino e o sentido de tudo. Será que podemos identificar o "Grande Irmão" que teima cotidianamente em realizar esse papel, ou melhor, os tantos "grandes irmãos" que permanentemente buscam impor seu sentido a tudo?

\section{A linguagem e a construção de uma identidade}

As palavras encontradas escritas em tabuinhas órficas, na Grécia por arqueólogos, hoje talvez não fizessem o mesmo efeito se encontradas pixadas em um muro: - Estou seco de sede e morro: mas dai-me, depressa, a água fresca que brota da fonte de Mnemósina. ${ }^{9}$ Esse é um efeito provocado muitas vezes pelo mundo digital. No afã de alcançar informações, tem se desprezado o conhecimento, e principalmente, a compreensão dos fatos históricos. O ser digital parece apenas consumir informação, não mais tem sede de dialogar com o conhecimento.

A memória dá vida e liberta. O ser que recupera o passado, conhece e recupera sua própria identidade, e com ela, também recupera e aperfeiçoa seu poder de linguagem, de comunicação, e sua capacidade de chegar onde deseja:

E com tudo isso o passado, mesmo com sua natureza alterável, jamais fora alterado. Tudo o que fosse verdade agora fora verdade

\footnotetext{
${ }^{8}$ ORWELL, George. 1984. Trad. De Alexandre Hubner e Heloisa Jahn. São Paulo: Companhia das Letras, 2009. P. 47.

${ }^{9}$ VERNANT, Jean-Pierre. As origens do pensamento grego. Rio de Janeiro: Bertrand Brasil, 2000. Trad. de Ísis Borges B. da Fonseca, 11ª . ed., 108p.
} 
desde sempre, a vida toda. Muito simples. O indivíduo só precisava obter uma série interminável de vitórias sobre a própria memória. "Controle da realidade", era a designação adotada. Em Novafala: "duplipensamento". ${ }^{10}$

Não é demais lembrar a lição de Castoriadis ao esclarecer que existem duas dimensões diferentes e obrigatórias da sociedade, de cada sociedade: a dimensão identitária e a dimensão propriamente imaginária. O tempo instituído como identitário é o tempo como tempo de demarcação, ou tempo das medidas. O tempo instituído como imaginário é o tempo da significação, ou tempo significativo. Enquanto o primeiro tem relação com a medida do tempo ou imposição ao tempo de uma medida (tempo calendário), com suas divisões numéricas apoiadas sobre os fenômenos periódicos (dia, mês lunar, estações, ano). Mas o tempo instituído imaginário mantém com o tempo identitário uma relação de reciprocidade, de modo que o tempo identitário só é "tempo" porque é referido ao tempo imaginário que lhe confere sua significação de "tempo". As sociedades, enfim, não vivem o tempo como simples calendário. É no tempo imaginário que são estabelecidos os limites do tempo e os períodos do tempo. ${ }^{11}$

A tentativa de exportação das "certezas" da Modernidade Ocidental, chegou a sugerir a formação lenta e gradual, determinante, biológica, de uma mundialização cultural, ou convergência mundial de todas as culturas. Hoje, ao contrário das "profecias absolutas" de dita modernidade, percebe-se no lugar de convergência, o que ocorreu foi o recrudescimento das diferenças, que sempre existiram, mas que agora buscam reconhecimento e respeito.

A cultura, hoje, no capitalismo transnacional (ou neocolonial) possui uma força "política" e entra em contradição com lógicas políticas ou econômicas, que tentam usá-la para exploração ou dominação - e aqui surge a crítica de teorias especialmente liberais que são o correlativo social da economia capitalista. Algumas reflexões sobre a diversidade, diz Boaventura de Souza Santos, levam a emergência de novos espaços de resistência e lutas e de novas práticas políticas, e a "política

\footnotetext{
${ }^{10}$ ORWELL, George. 1984. Trad. De Alexandre Hubner e Heloisa Jahn. São Paulo: Companhia das Letras, 2009. P. 47.

${ }^{11}$ CASTORIADIS, Cornelius. A instituição imaginária da sociedade. Rio de Janeiro: Paz e Terra, 1982. p. 246-247.
} 
multicultural" é um resultado disso. ${ }^{12}$

Ora, sem a diferença, não é possível o diálogo. Daí o horror que causa a sugestão de Orwell de um tempo completamente instituinte e imaginário que cria as certezas, solidifica a razão, converte o que é posto em dúvida e elimina o poder de linguagem, a fala, e o que é mais aterrador, até mesmo o silêncio, que como aprendeuse a partir de Heidegger e Gadamer, também tem muito a dizer.

\section{4. “1984” e os Cursos Jurídicos}

A atualidade da obra revela-se sobremodo para o pensar crítico sobre os cursos de Direito. A obra reforça junto aos cursos jurídicos a importância das disciplinas propedêuticas, História, Ciência Política, Antropologia e também de Língua Portuguesa, e ainda de Linguagem Jurídica e Argumentação Jurídica, que revelam, diante dos perigos que a limitação ou desconhecimento sobre a linguagem produz, o valor inestimável para a carreira jurídica. O jovem jurista que pretende dominar o conteúdo do Direito precisa compreender que o domínio parte inicialmente da própria linguagem.

Nesse sentido, a importância da obra é indiscutível, fundamental para todo Curso de Direito que pretenda-se libertador, que vise a emancipação do ser humano. Para um Curso de Direito e um estudante de Direito a obra “1984” de George Orwell serve como um aviso, como uma importante mensagem de perigo que qualquer um corre através do ensinar e do aprender na área jurídica. O perigo circula sempre ao lado do mau uso da linguagem, e mau uso que inclui em primeira instância a própria incapacidade de seu manuseio.

Surgida após a Segunda Guerra Mundial, a obra “1984” revela-se um instrumento extremamente eficaz de alerta para todos, como outras obras também se revelam, mostrando como um pensamento, uma ideia, uma ideologia, pode ser

\footnotetext{
${ }^{12}$ SANTOS, Boaventura de Souza. Reconhecer para libertar: os caminhos do cosmopolitismo multicultural. Coleção Reinventar a Emancipação Social: para novos manifestos. v. 3. Rio de Janeiro: Civilização Brasileira, 2003. p. 27 e 35.
} 
construída e sedimentada junto a um grupo social, e como é possível moldar-se pessoas para determinados fins previamente planejados.

Pode-se observar muitos Cursos de Direito com um programa e conteúdo programático que envolvem disciplinas e metodologias que propiciam a crítica, entretanto, observa-se também que muitas vezes um trabalho ainda intenso deve ser realizado antes do estabelecimento da crítica, que é o desenvolvimento da própria motivação dos estudantes para a crítica, uma vez que eles ingressam na Faculdade com uma sede impressionante mas exclusiva de conhecer a Lei.

É extremamente importante, assim, possibilitar que essa sede seja saciada, mas em conjunto com o problema que traz, ou seja, o perigo de se cair no pensamento exclusivamente apodítico, onde o Direito é visto como uma verdade exclusivamente normativista - e é esta que por incrível que pareça, seduz os estudantes, que muitas vezes buscam o Direito pelo poder que ele representa. E "poder", para os jovens estudantes, significa "captar" a "verdade" da Lei. Pior ainda, quando pensam que basta desenvolver capacidades "oratórias" que levem a algum resultado imediato. Mal que já levou Cícero a aconselhar:

\begin{abstract}
Mas que se reduza as funções do orador a saber falar com verbosidade perante o pretor ou os juízes, o povo ou o senado; ao orador, assim definido, um grande número de conhecimentos são ainda necessários, será preciso reconhece-los. (...) A arte de bem dizer supõe, necessariamente, para o que fala, o exame anterior e cada vez mais aprofundado do sujeito de que se fala. (...) Toda a diferença provém dessa vantagem, que as pessoas eloquentes possuem: uma elocução bem ordenada, realçada pelos ornamentos e o polimento da arte. Mas esta elocução, se não tem por apoio um conhecimento exacto e completo das coisas, eu afirmo que ou não será nada ou apenas provocará o riso do auditório. ${ }^{13}$
\end{abstract}

Infelizmente, o mundo contemporâneo e digital parece não ter mais tempo para um conhecimento delicado e profundo da história humana, e mesmo, para o aperfeiçoar e aprofundar o conhecimento do ser em si que é o humano, e bem assim, sua própria capacidade linguística. Na medida em que o ser humano deixa de se

\footnotetext{
${ }^{13}$ CÍCERO. Do Orador - e Textos Vários. Trad. Fernando Couto. REsjurídica: Porto, s/d. p. 38-39.
} 
preocupar em conhecer seu passado, deixa se ter maior capacidade linguística e bem assim, deixa de ter maior capacidade comunicativa.

É uma roda intermitente de consequências. A própria sede de história, de saber, de passado, também diminui, assim como o ser se torna mais bruto e menos capaz de linguagem. No passado tabuinhas órficas conseguiam incentivar jovens a matar a sede sobre seu próprio passado, porque acreditava-se que através do conhecimento do passado seria possível alcançar respostas sobre o sentido do ser no mundo.

Vive-se em uma época de digitalização e de "web" letrados, onde a efemeridade de tudo traz a sensação de que tudo é transitório, inclusive as instituições jurídicas. Entretanto, essa é uma sensação enganosa, e deve-se estar apto para perceber o que é uma tradição que tende a se manter e uma instituição que se transforma, daquilo que efetivamente não é permanente.

\section{Atualidade de “1984” para os operadores jurídicos digitais}

A tradição do sujeito "conhecedor da Lei” remonta há séculos ainda antes do império Romano. É certo que na época da República Romana já os “conhecedores da Lei" eram sacerdotes, aqueles que tinham uma aptidão especial para apreender os desígnios e sinais da lei, e bem assim, seu significado. Mesmo sem conhecer a origem do Direito, essa é a imagem que seduz os jovens sem que sequer conhecem a história. História, que aliás, têm cada vez mais, desaparecido dos conteúdos dos cursos de Direito.

Hoje, entretanto, é necessário desmascarar essa "potência" do jurista, e revelar a verdadeira função do jurista. $\mathrm{O}$ intérprete jurídico antes de aplicar um método ao texto, considerando o texto como que um objeto a ser interpretado, não apropria-se de mais um objeto que acumula à sua biblioteca de conhecimento. Ele é antes, como revela Palmer, "possuído pelas pretensões que o texto tem de o orientar. Por outras 
palavras, interpretar quer a vontade de Deus quer a Sua lei não é uma forma de dominar o tema mas de o servir."

Para uma cultura jurídica que necessita cada vez mais de operadores que saibam manipular teclas, senhas e conexões wi fi, não é de se estranhar que muitas vezes pareça que o uso instrumental do direito possa ser a solução. Entretanto, a instrumentalidade sempre será a instrumentalidade, e nada mais do que isso, ou seja, o modo como se pode alcançar determinado fim, que, de todo modo, deve estar bastante claro para o operador do direito. Isso implica em, muito mais do que conhecer e compreender as engrenagens do sistema jurídico, e principalmente, para os dias de hoje, comunicar-se através dos meios digitais, compreender o sentido fundamental do direito para si próprio, e a partir de uma visão crítica de si próprio - do operador - e do próprio mundo jurídico de que se cerca, caminhar na seara jurídica.

Se por um lado, por muito tempo houve a crítica do Direito e do operador do Direito como distantes da realidade social, agora a mesma crítica se repete, pois o operador muitas vezes está tão restrito às engrenagens do processo digital e da estrutura legal que tende a esquivar-se da dura realidade social e da verdadeira luta pelo Direito. E qual seria mesmo, a verdadeira luta pelo Direito?

É possível perceber que o único espaço privado que ainda não foi destruído completamente, e que ainda sobrevive, é o das redes sociais, que infelizmente, também corre o risco de implodir por ameaças que lhe vêm tanto de fora quanto do próprio público que a utiliza (no sentido de que há um grave comprometimento da informação que deve circular pela exagerada necessidade da maioria absoluta dos internautas de noticiarem apenas a si próprios).

Enfim, se nem mesmo em plena liberdade, é possível conhecer a realidade, sabendo-se da dependência que existe entre o perceber, conhecer, compreender e viver a linguagem, imagine-se o que seria a dificuldade - na verdade impossibilidade - de conhecimento sem liberdade plena no uso da pobre linguagem que foi

\footnotetext{
${ }^{14}$ PALMER, Richard E. Hermenêutica. Trad. de Maria Luísa Ribeiro Ferreira. Edições 70: Lisboa, 1997. p. 237-238.
} 
desenvolvida entre os seres humanos, a contar pelo menos do século 25 antes de Cristo. Afinal, pensando bem, não faz tanto tempo assim que o ser humano desenvolveu uma linguagem própria para comunicação, especialmente escrita, se comparado como tempo que já estava ativo e produzindo da Terra.

Fica, para o final, a pergunta posta por Gadamer: "Está desapareciendo el arte de la conversación? No observamos en la vida social de nuestro tiempo una creciente monologización de la conducta humana? Es un fenómeno general de nuestra civilización que se relaciona con el modo de pensar científico-técnico de la misma?" 15 O ser humano, que é por natureza dotado de linguagem, está efetivamente comunicando menos? Afinal, não obstante a capacidade natural do ser humano para a linguagem, esta só se dá no diálogo, como apontou Gadamer, e quanto a isso, a obra 1984, e sempre toda estrutura política, tem muito a nos dizer.

\section{REFERÊNCIAS BIBLIOGRÁFICAS}

CALMON DE PASSOS, J.J. Revista de Processo, v. 102. Instrumentalidade do Processo e devido processo legal. São Paulo, 2001.

CÍCERO. Do Orador - e Textos Vários. Trad. Fernando Couto. REsjurídica: Porto, s/d.

GADAMER, Hans-Georg. Verdad y método. II. 2a. ed. Trad. Manuel Olasagasti. Sígueme: Salamanca, 1994.

ORWELL, George. 1984. Trad. De Alexandre Hubner e Heloisa Jahn. São Paulo: Companhia das Letras, 2009.

PALMER, Richard E. Hermenêutica. Trad. de Maria Luísa Ribeiro Ferreira. Edições 70: Lisboa, 1997.

VERNANT, Jean-Pierre. As origens do pensamento grego. Rio de Janeiro: Bertrand Brasil, 2000. Trad. de Ísis Borges B. da Fonseca, 11 a . ed., 108p.

WARAT, Luis Alberto. Introdução geral ao direito I: interpretação da Lei, temas para uma reformulação. Sérgio Fabris: Porto Alegre, 1984.

${ }^{15}$ GADAMER, Hans-Georg. Verdad y método. II. 2a. ed. Trad. Manuel Olasagasti. Sígueme: Salamanca, 1994. p. 203. 
WARAT, Luis Alberto. A ciência jurídica e seus dois maridos. 2a. ed. Santa Cruz do Sul: EDUNISC, 2000. 